\title{
Flat colorectal sessile serrated polyp: an example of what artificial intelligence does not easily detect
}

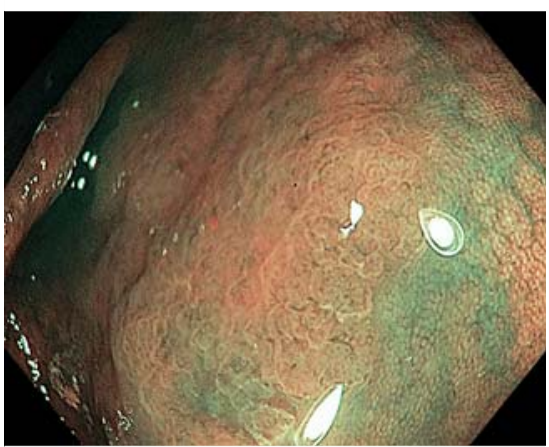

- Fig. 1 Endoscopic aspect of the first flat sessile serrated adenoma/polyp situated in the transverse colon (narrow-band imaging view).

In recent years, image recognition using artificial intelligence with deep learning has dramatically improved and opened the door to more detailed image analysis and real-time application in various medical fields [1,2]. In the colorectal cancer screening area, real-time computer-aided detection systems can lead to significant increases in both polyp and adenoma detection rates [3]. The ENDO-AID CADe program working in combination with the EVIS $\mathrm{X} 1$ video column (Olympus, Tokyo, Japan) is also able to provide visual support during the screening process, making endoscopy easier and more efficient.

First, we report the case of a 59-year-old woman referred to our center for colonoscopy surveillance post-polyp resection 3 years ago. She underwent magnifying colonoscopy (HQ 190 with EVIS X1 video column; Olympus, Tokyo, Japan) and chromoendoscopy. After careful analysis, we detected an 18-mm flat sessile serrated adenoma/polyp in the transverse colon ( $\mathbf{F i g . 1}$ ). The Olympus computer-aided detection system revealed difficulties in detecting the lesion, even after the mucus adhering to the

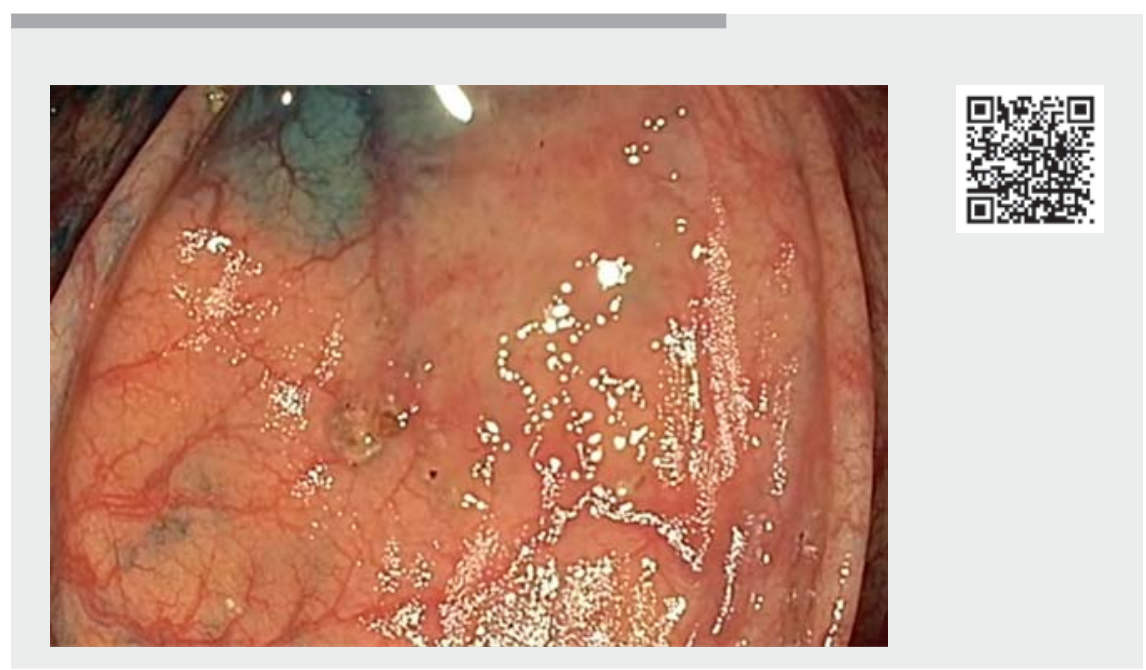

Video 1 Endoscopic diagnosis of the two flat sessile serrated adenoma/polyps.

mucosa was washed away and after various approach attempts with the endoscope ( Video 1 ).

A second case of a 61-year-old man referred to our center for the same reason showed that a 6-mm flat sessile serrated adenoma/polyp was detected by the program only after washing away the mucus ( $\triangleright$ Video 1). Despite its great value for the human eye to detect a sessile serrated adenoma/polyp, mucus could be a false friend for computer-aided detection systems and lead to less visible edges and non-detection of the elevated shape. These cases illustrate that human detection still has a role to play, but for how long? As artificial intelligence becomes more and more powerful, humans will probably have to focus mainly on colon surface exploration. In any case, artificial intelligence should always be considered a tool and will never completely replace physicians.

Endoscopy_UCTN_Code_CCL_1AD_2AJ
Competing interests

The authors declare that they have no conflict of interest.

The authors

Pierre Lafeuille ${ }^{1}$, Thomas Lambin ${ }^{1}$, Clara Yzet $^{2}$, El Houcine Latif ${ }^{3}$, Nathan Ordoqui ${ }^{3}$, Jérôme Rivory ${ }^{1}$, Mathieu Pioche ${ }^{1}$

1 Department of Endoscopy and HepatoGastroenterology, Edouard Herriot Hospital, Lyon, France

2 Department of Endoscopy and HepatoGastroenterology, Amiens University Hospital, Amiens, France

3 Yansys Medical, Vichy, France

Corresponding author

Mathieu Pioche, MD

Endoscopy Unit - Digestive Disease Department, Pavillon L - Edouard Herriot Hospital, 69437 Lyon Cédex, France mathieu.pioche@chu-lyon.fr 


\section{References}

[1] Tsuboi A, Oka S, Aoyama K et al. Artificial intelligence using a convolutional neural network for automatic detection of smallbowel angioectasia in capsule endoscopy images. Dig Endosc 2020; 32: 382-390. doi: $10.1111 /$ den. 13507

[2] Hirasawa T, Aoyama K, Tanimoto T et al. Application of artificial intelligence using a convolutional neural network for detecting gastric cancer in endoscopic images. Gastric Cancer 2018; 21: 653-660. doi:10.1007| s10120-018-0793-2
[3] Wang P, Berzin TM, Glissen Brown JR et al. Real-time automatic detection system increases colonoscopic polyp and adenoma detection rates: a prospective randomised controlled study. Gut 2019; 68: 1813-1819. doi:10.1136/gutjnl-2018-317500

Bibliography

Endoscopy 2022; 54: 520-521

DOI 10.1055/a-1486-6220

ISSN 0013-726X

published online 12.5 .2021

(c) 2021. Thieme. All rights reserved.

Georg Thieme Verlag KG, Rüdigerstraße 14,

70469 Stuttgart, Germany

\section{ENDOSCOPY E-VIDEOS}

https://eref.thieme.de/e-videos

口回 Endoscopy E-Videos is an open access online section, 回: reporting on interesting cases and new techniques in gastroenterological endoscopy. All papers include a high quality video and all contributions are freely accessible online. Processing charges apply (currently EUR 375), discounts and wavers acc. to HINARI are available.

This section has its own submission website at

https://mc.manuscriptcentral.com/e-videos 